\title{
Impact of microRNAs in Resistance to Chemotherapy and Novel Targeted Agents in Non-Small Cell Lung Cancer
}

\author{
Christian Rolfo ${ }^{1, \#}$, Daniele Fanale, ${ }^{2, \#}$, David S. Hong ${ }^{3}$, Apostolia M. Tsimberidou ${ }^{3}$, \\ Sarina A. Piha-Paul ${ }^{3}$, Patrick Pauwels ${ }^{4}$, Jan P. Van Meerbeeck ${ }^{5}$, Stefano Caruso ${ }^{2}$, \\ Viviana Bazan ${ }^{2}$, Giuseppe Cicero ${ }^{2}$, Antonio Russo ${ }^{2}$ and Elisa Giovannetti, ${ }^{6}$
}

\author{
${ }^{I}$ Phase I- Early Clinical Trials Unit, Oncology Department and Multidisciplinary Oncology Center Antwerp (MOCA) \\ Antwerp University Hospital, Edegem, Belgium; ${ }^{2}$ Medical Oncology, Department of Surgical and Oncology Sciences, \\ University of Palermo, Palermo, Italy; ${ }^{3}$ Clinical Center for Target Therapy, Phase I Program, MD Anderson Cancer \\ Center, Houston, USA $;^{4}$ Molecular Pathology Unit, Pathology Department and MOCA, Antwerp University Hospital, \\ Edegem Belgium; ${ }^{5}$ Thoracic Oncology and MOCA, Antwerp University Hospital, Edegem, Belgium ${ }^{6}$ Department of \\ Medical Oncology, VU University Medical Center-Amsterdam, The Netherlands
}

\begin{abstract}
Despite recent advances in understanding the cancer signaling pathways and in developing new therapeutic strategies, non-small cell lung cancer (NSCLC) shows grim prognosis and high incidence of recurrence. Insufficient disruption of oncogenic signaling and drug resistance are the most common causes of tumor recurrence. Drug resistance, intrinsic or acquired, represents a main obstacle in NSCLC therapeutics by limiting the efficacy both of conventional chemotherapeutic compounds and new targeted agents. Therefore, novel and more innovative approaches are required for treatment of this tumor. MicroRNAs (miRNAs) are a family of small non-coding RNAs that regulate gene expression by sequence-specific targeting of mRNAs causing mRNA degradation or translational repression. Accumulating evidence suggests that impairment of candidate miRNAs may be involved in the acquisition of tumor cell resistance to conventional chemotherapy and novel biological agents by affecting the drug sensitivity of cancer cells. The modulation of these miRNAs, using antagomiRs or miRNA mimics, can restore key gene networks and signaling pathways, and optimize anticancer therapies by inhibition of tumor cell proliferation and increasing the drug sensitivity. Therefore, miRNA-based therapeutics provides an attractive anti-tumor approach for developing new and more effective individualized therapeutic strategies, improving drug efficiency, and for predicting the response to different anticancer drugs. In this review, we present an overview on the role of miRNAs in resistance mechanisms of NSCLC, discussing the main studies on the aberrations in apoptosis, cell cycle and DNA damage repair pathways, as well as in novel drug targets.
\end{abstract}

Keywords: Chemotherapy, lung cancer, microRNA, oncogenic pathways, resistance, targeted agents.

\section{INTRODUCTION}

Lung cancer is the first cause of cancer deaths worldwide, among both men and women [1]. Approximately $80 \%$ to $90 \%$ of people with lung cancer have non-small-cell lung cancer (NSCLC), including adenocarcinoma, squamous cell carcinoma, large cell carcinoma, and several other types that occur rarely [2]. Despite recent advances in surgerical procedures, radiotherapy, chemotherapy and the advent of targeted therapies, NSCLC have an overall 5-year survival rate of about $16 \%$ and high incidence of recurrence [1]. The explanation for this poor prognosis is attributable to the high percentage of patients diagnosed with advanced-stage disease but also to the primary/secondary resistance to current treatments. Although different mechanisms are associated with

*Address correspondence to this author at the Department of Medical Oncology, VU University Medical Center, Cancer Center Amsterdam, CCA room 1.42, De Boelelaan 1117, 1081 HV Amsterdam, The Netherlands; Tel: (31) - 20 - 4442267; Fax: (31) - 20 - 4443844;

E-mails: e.giovannetti@vumc.nl; elisa.giovannetti@gmail.com

${ }^{\#}$ Christian Rolfo and Daniele Fanale have contributed equally to this work. chemoresistance and several studies have been performed, today, we are still far from fully understanding how to prevent or overcome drug resistance. Hence, we need to expand the knowledge on the molecular mechanisms of chemoresistance and drug toxicity, in order to increase the effectiveness of current therapeutic strategies or alternatively to create new approaches which can improve the life expectancy of patients affected by lung cancer.

Tumors can be intrinsically insensitive to therapeutic agents prior to therapy, or resistance may be acquired after treatment by tumors that are initially sensitive [3] http://www.ncbi.nlm.nih.gov/pubmed/22912349. Until today, various mechanisms, responsible for the drug resistance, have been proposed, including increased drug efflux, drug metabolism/inactivation, drug target alterations, DNA repair, or apoptosis deficiency [4-6]. Frequently, drug resistance can be related to higher expression levels of ATP binding cassette $(\mathrm{ABC})$ transporter proteins, such as P-glycoprotein (Pgp). Overexpression of $\mathrm{ABC}$ transporters can decrease intracellular accumulation, thereby conferring resistance to drug. This phenomenon, which alters the response to differ- 
ent therapeutic agents, is called "multi-drug resistance" (MDR) [7]. Although drug efflux is the main mechanism correlated to drug resistance, the altered expression of enzymes which cause drug inactivation can decrease the amount of free drug available to bind its cellular target [8]. In addition, the mutational status of drug targets plays a pivotal role in the effectiveness of the therapeutic treatment. For example, it has been reported that thymidylate synthase (TS) gene amplification, a pemetrexed target, is associated with resistance to this drug [9]. Furthermore, approximately $70 \%$ of patients resistant to gefitinib and erlotinib, EGFR tyrosine kinase inhibitors (TKIs), have the secondary EGFR T790M mutation or the amplification of c-Met [10]. In some cases, drug resistance in tumors, including NSCLC, may be due to defects in DNA-repair pathways, such as nucleotide excision-repair (NER) [11, 12], mismatch-repair (MMR) [13], base excision-repair (BER) [14], non-homologous endjoining (NHEJ) [15] and homologous-recombination (HR) [16]. Moreover, it is important to emphasize that the loss of intracellular death mechanisms, including apoptotic pathways, causes tumor cell survival and cancer progression by making the cells resistant to therapeutic agents [17].

In recent years, scientific research has focused on genetic and epigenetic alterations responsible for drug resistance. In particular, it has been reported that mutations, translocations, amplifications, deletions, DNA hypermethylation and histone post-translational modifications may have a key role in drug resistance [18]. Recently, several evidence showed that microRNAs (miRNAs) are also capable of modulating sensitivity/resistance to conventional or targeted anticancer drugs and, for this reason, miRNA-based gene therapy could provide an innovative anti-cancer strategy.

\section{MiRNA FUNCTION AND BIOGENESIS}

MiRNAs are a class of small non-coding RNA molecules, approximately 20-25 nucleotides in length, evolutionarily conserved, encoded by cell endogenous genes [19]. MiRNAs negatively regulate gene expression via translational repression or mRNA degradation, through base pairing to a partially complementary site, mostly in the 3' untranslated region (UTR), of the target messenger RNAs (mRNAs) [20]. Since the discovery of miRNAs in the early 1990s, in Caenorhabditis elegans, thousands of miRNAs have been identified and more than 1000 miRNAs have been detected in humans [21]. miRNAs are involved in the regulation of a many biological processes, such mechanisms of embryonic development, cell differentiation, apoptosis, cell growth control and metabolic processes. Indeed, recent bioinformatic and experimental evidence have estimated that about $30 \%$ of human genes undergoes miRNA-mediated regulation [22]. Given that they control the regulation of crucial biological functions, it is easy to understand that miRNAs are also involved in different pathological conditions, such as cancer [22]. Moreover, a single miRNA may regulate the expression of a large number of genes, and a single mRNA can be target of multiple miRNAs [23].

miRNA biogenesis is the multistep process of creating a mature and functional miRNA from a miRNA gene. These genes are located in introns or exons of a protein-coding gene or in the intergenic regions. It is known that their tran- scription is performed by RNA polymerase II or RNA polymerase III which transcribe for a long primary transcript called pri-miRNA, an inactive form of about $1 \mathrm{~Kb}$ in length $[24,25]$. The pri-miRNA is then processed by the microprocessor complex consisting of Drosha, an RNase III endonuclease, its partner DGCR8 and associated proteins, into an approximately 70-90-nucleotide incomplete, hairpin-like, miRNA precursor (pre-miRNA) [26]. Pre-miRNAs are exported from the nucleus into the cytoplasm by Exportin-5. Once in the cytosol, pre-miRNAs are then cleaved by Dicer, an RNase III endonuclease, to generate a 19- to 23nucleotide RNA duplex. This double strand RNA binds the protein Argonaute and it is incorporated in the protein complex termed RNA-induced silencing complex (RISC). One of the two filaments (filament guide) remains with Argonaute and constitutes the mature miRNA, while the other strand (passenger strand) is degraded. At this point, the mature miRNA may negatively regulate one or more mRNA targets by binding to specific sequences at the 3' UTR [27]. MiRNAs regulate gene expression through two different mechanisms depending on the complementarity between the miRNA and its target site. When there is perfect complementarity, miRNA determines the mRNA degradation, whereas it causes arrest of the translation when the complementarity is partial [20, 27] (Fig. 1).

\section{MiRNAS AND CANCER}

During biogenesis miRNAs are subject to intense transcriptional and post-transcriptional regulation. MiRNA expression is regulated by different mechanisms such as specific translational regulation, histone deacetylation and methylation, DNA copy alteration and gene mutations affecting proteins regulating miRNA maturation [22, 28]. Moreover, a significant number of miRNA genes are located close to fragile sites of chromosomes and in genomic regions which are more prone to amplification, deletion or amutations and which may interfere with miRNA function [22]. Therefore, alterations of miRNA expression have been described in several pathological conditions and many miRNAs have been associated with the development of different cancers but also with biological aggressiveness, metastatic capacity and resistance to antitumor treatments. The impact of miRNAs in cancer was firstly evaluated in leukaemia, where miRNA genes were found to be specifically deleted [29]. Since then, several studies carried out in order to investigate the involvement of miRNAs in various cancers, including NSCLC. MiRNAs involved in tumorigenesis may have two different roles. MiRNA oncogenes, called oncomirs, promote tumor development through the negative regulation of tumor suppressor genes. Alternatively, tumor suppressor microRNA, called anti-oncomiRs, are able to inhibit tumor growth by targeting oncogenes [30]. For these reasons, oncomiRs are up-regulated in cancer cells while anti-oncomiRs are down-regulated. For example, miR-21 is overexpressed in various cancers, including NSCLC, and acts as oncomiR by targeting genes related to proliferation, cell death, and invasion such as Apaf1, Faslg and RhoB, that are involved in the intrinsic/extrinsic apoptotic pathways [31]. Conversely, another study reported that let-7, an anti-oncomiR, has low expression in lung cancer compared to normal lung tissue, and that let-7 expression is inversely correlated with RAS 


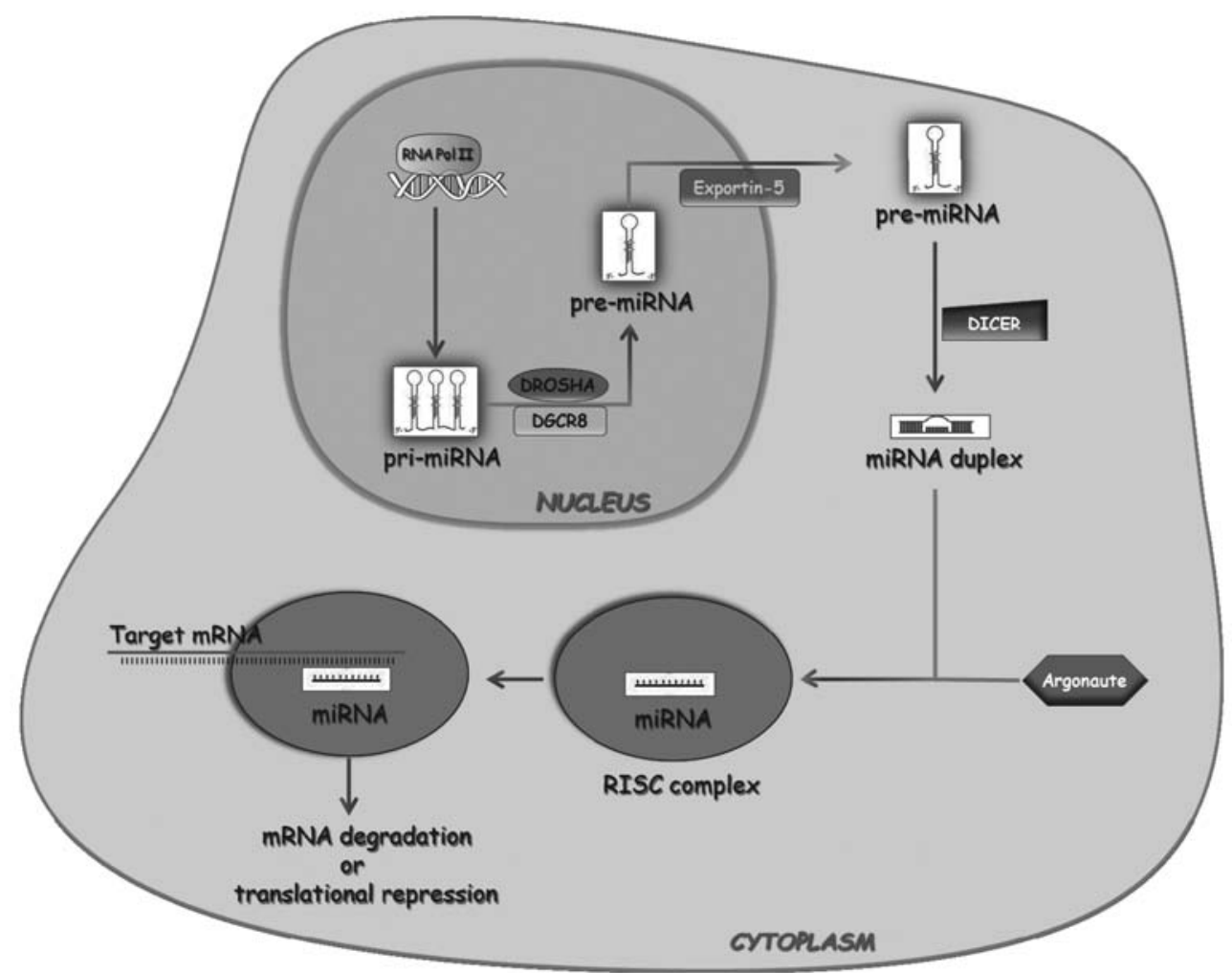

Fig. (1). Schematic overview of the microRNA biogenesis pathway. MicroRNAs biogenesis is a coordinated process regulated by different groups of enzymes and associated proteins in the nucleus and cytoplasm.

expression in lung cancer samples [32]. Furthermore, it has been reported that miRNA expression is associated with survival in lung cancer. Yanaihara and collaborators identified 43 differentially expressed miRNAs between lung cancer tissues and adjacent normal tissues and they showed that elevated miR-155 and low let7a-2 expression were correlated to shorter survival [33]. Subsequently, Yu et al. described a 5-miRNA signature correlated with disease free survival in 112 NSCLC patients [34].

\section{MiRNAS AND DRUG RESISTANCE}

Drug resistance represents a substantial obstacle in cancer treatment by reducing the efficacy both of conventional chemotherapeutic drugs and novel targeted agents [35]. Increasing evidence suggests that drug-induced dysregulation of miRNA function might be involved in the acquisition of chemoresistance by modulating the sensitivity of cancer cells to anticancer drugs $[18,36,37]$. However, the mechanisms by which miRNAs affect drug sensitivity or resistance of tumor cells are not yet fully elucidated. Thus, MiRNA expression profile analysis could be useful to predict and improve drug activity, developing new individualized therapies [38]. The up- or down-regulation of miRNAs affects the expression of several target proteins involved in drug response, determining changes in drug sensitivity through different molecular mechanisms. These proteins could be drug targets, transporters, or components related to cell cycle and apoptosis or other key cellular signaling pathways. Hence, the new approaches to predict the drug response should integrate the miRNA and mRNA expression profiles, considering several potential molecular biomarkers. Further studies should aim to identify specific miRNA signatures related to drug resistance, by comparing the miRNA expression patterns of sensitive and resistant cells.

Furthermore, targeting miRNAs is an emerging field for optimization of anti-cancer treatments in order to inhibit tumor cell proliferation and to increase the sensitivity to chemotherapy [39]. MiRNA expression may be regulated not only by targeting specific miRNAs to restore drug sensitivity, but also by activation of tumor suppressor miRNAs and inactivation of oncogenic miRNAs. Since aberrant expression of miRNAs is involved in the development of chemoresistance, correcting these deregulations may provide a therapeutic benefit. Several reports have shown that antisense oligonucleotides, called anti-miRNAs (anti-miRs) or miRNA antagonists (antagomiRs), can block the function of miRNAs [40, 41]. Interestingly, in vivo experimental studies showed that use of anti-RNAs against specific oncogenic miRNAs induced a significant decrease in their expression levels in different tissues, resulting in upregulation of related target genes [42]. Therefore, targeting selected miRNAs could be an innovative therapeutic strategy for anti-cancer therapy in order to abolish drug resistance of cancer cells or eliminate cells that are usually resistant to conventional therapies, including cancer stem cells (CSCs) [43-47]. Another mechanism by which miRNAs can modulate the drug sensitivity involves the restoration in expression levels of tumor suppressor miRNAs with miRNA mimics [22]. For example, the in vitro transfection of lung cancer cells with let-7 pre-miR induced upregulation of let-7 tumor suppressor miRNA and 
the inhibition of cell proliferation [48]. To date, several studies have shown that miRNA mimics and anti-miRNAs may be useful to restore physiological gene networks in different cancer cells and in vivo models, suggesting a new potential role in anti-cancer therapy [49]. However, use of synthetic oligonucleotides shows some limitations due to their rapid degradation and lack of suitable in vivo delivery systems. These limitations can be overcome by use of natural agents, including curcumin, epigallocatechin-3-gallate (EGCG), isoflavone, indole-3-carbinol (I3C) and 3,3'-diinodolylmethane (DIM) $[50,51]$. For example, the I3C natural agent modulates miR-21 in A549 NSCLC cells, by reducing the expression levels of this miRNA and increasing the expression of miR-21 target proteins, such as PDCD4, PTEN, and RECK [52]. Similar studies revealed that natural chemopreventive agents that showed no human toxicity might regulate miRNA expression, suggesting that their combination with chemotherapy could be a new therapeutic approach [53, 54]. To date, there are not reports on clinical trials that exploit the miRNA approach in order to modulate drug sensitivity for cancer therapy. However, several phase II clinical trials are ongoing to analyze miRNA expression profiles in patients treated with several chemotherapy regimens, including docetaxel, carboplatin, cisplatin, paclitaxel, erlotinib, and cetuximab, which are the most used chemotherapeutic agents in clinical trials for NSCLC [54].

\section{MiRNAS AND RESISTANCE TO CONVENTIONAL CHEMOTHERAPY IN NSCLC}

Conventional chemotherapy represents the primary therapeutic strategy for most NSCLC and the poor prognosis of NSCLCs is mainly due to the failure of chemotherapeutic regimens because of intrinsic or acquired resistance mechanisms [35]. Resistant cancer cells cannot be destroyed by chemotherapeutic regimens, resulting in side-effects and poor prognosis. Novel biomarkers to select patient groups with high risk of therapeutic treatment failure are warranted. Therefore, in the present review we describe several specific miRNAs, which have been associated with drug resistance in NSCLC by controlling different signaling pathways, including cell cycle, survival, cell proliferation, apoptosis and DNA damage repair (Table $\mathbf{1}$ ).

\subsection{MiRNAs Involved in Chemoresistance through Cell Apoptosis Regulation}

Cell apoptosis is a complex process that may be achieved through the death-receptor or the mitochondria pathways $[55,56]$. Most antitumor drugs such as antimetabolites, and alkylating agents inhibit cancer proliferation by promoting cell apoptosis or cell cycle arrest. A decreased susceptibility to drug-induced apoptosis causes the development of a drugresistant phenotype in several cancer cells [57]. Frequently, apoptosis inhibition is induced by upregulation of antiapoptotic proteins, such as BCL2, BCL-XL, XIAPs, MET, PED/PEA-15 (PED), and tumor suppressors, such as p53, PTEN, APC, and by lower expression of pro-apoptotic proteins, such as BAX, BAD, BID, NOXA [58, 59]. Expression variations of these molecules are affected by the miRNA dysregulation. In recent years research performed on different types of cancer, allowed to identify a set of miRNAs correlated with drug sensitivity and involved in cell apoptosis regulation, including let-7a, miR-15b/16, miR-27a, miR-34, miR-130a, miR-199, miR-214, miR-221/222, miR-337 and miR-451 [58, 60, 61]. Since a single miRNA can control the sensitivity to a wide number of anticancer drugs, miRNAs could exert their protective function through survival pathways that inhibit downstream activity of many anticancer compounds.

Docetaxel and paclitaxel belong to family of taxanes and are important microtubule-targeting anticancer agents commonly used in the therapy of advanced NSCLC. They inhibit microtubule dynamics by preventing the microtubule depolymerization, leading to arrest of mitosis in metapahase, activation of the spindle assembly checkpoint, and thus inducing apoptosis [62-64]. Chemoresistance remains the most important obstacle limiting their clinical applications, and deregulation of molecules involved in the apoptosis pathways is an important mechanism by which miRNAs cause resistance to microtubule-targeting agents. Rui and collaborators reported that the expression of three miRNAs (miR200b, miR-194 and miR-212) was significantly downregulated, while the expression of three other miRNAs (miR192, miR-424 and miR-98) was significantly up-regulated in docetaxel-resistant SPC-A1 NSCLC cells, suggesting differential miRNA expression profiles in docetaxel-resistant and sensitive tumors [65]. Subsequently, Feng and collaborators showed that miR-200b is the most down-regulated miRNA in docetaxel-resistant NSCLC cells and it might act as a tumor suppressor to reverse docetaxel resistance, by targeting E2F3, whose function is important for the correct cell cycle progression [66]. Others studies showed that miR-192 acts as a tumor suppressor by modulating the RB1 gene to inhibit cell proliferation and induce apoptosis [67], whereas upregulation of $\mathrm{miR}-135 \mathrm{a}$ and $\mathrm{miR}-34 \mathrm{c}-5 \mathrm{p}$ was correlated with resistance to apoptosis induction by paclitaxel. In particular, increased expression of miR-135a, both in vivo and in vitro, induced down-regulation of its direct target, $A P C$, and increased resistance to paclitaxel [68], while miR-34c-5pmediated down-regulation of BMF (Bcl-2-modifying factor) together with cMyc contributed to resistance to paclitaxelinduced apoptosis through TP53 down-regulation in A549 NSCLC cells, [69]. Furthermore, in human NCI-H1155 NSCLC cells, that are resistant to paclitaxel, introduction of a miR-337-3p mimic re-sensitizes the cells to paclitaxel by increasing the ability of the drug to determine G2/M block and apoptosis [70]. STAT3 and RAPIA were reported as targets of miR-337-3p. STAT3 is a transcription factor involved in angiogenesis, invasion, tumor cell survival, and drug resistance. Its targets include proteins that control cell survival, such as cyclin D1, c-myc, survivin, Bcl-2, and p21cip1 [71]. The down-regulation of STAT3 and RAP1A by miR-337-3p demonstared that STAT3 and RAP1A influence the effect of miR-337-3p on paclitaxel sensitivity [58].

In addition, other miRNAs are involved in resistance to apoptosis induced by platinum-derived anticancer agents. An in vitro study demonstrated that miR-181a and miR-630 modulate cell death induced by cisplatin in lung cancer cells [72]. In particular, miR-181a and miR-630 control apoptosis through the mitochondrial/post-mitochondrial steps of the intrinsic pathway, including BAX oligomerization, mitochondrial transmembrane potential alteration, and proteolytic activation of caspase-3 and caspase-9 [72]. 
Table 1. MicroRNAs involved in resistance to conventional chemotherapy.

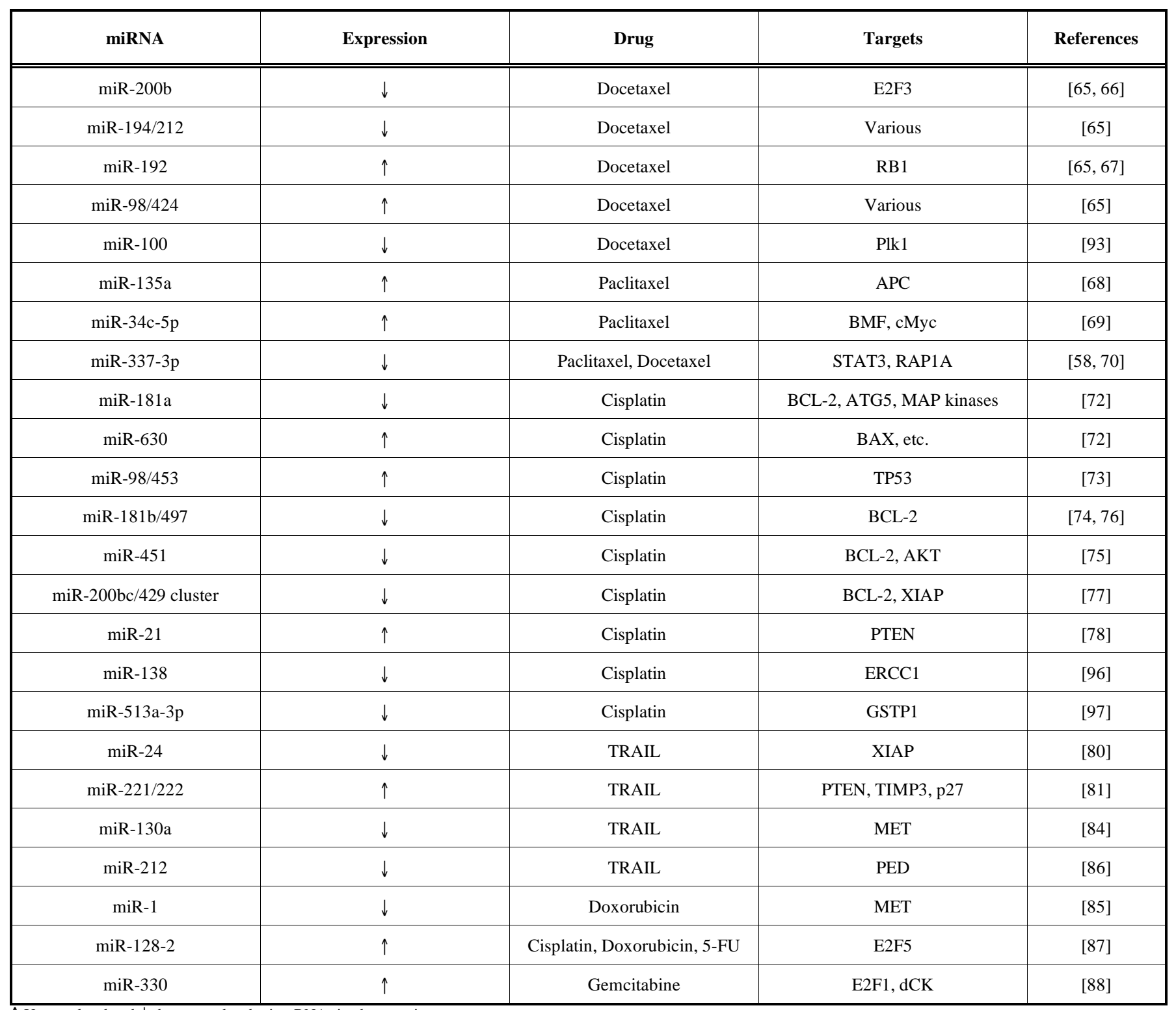

$\uparrow$ Up-regulated and $\downarrow$ down-regulated microRNAs in chemoresistance.

Recently, Zhang and collaborators reported that miR-98 and miR-453 increased resistance to cisplatin by downregulating TP53 expression, in A549 cells [73]. Furthermore, several reports showed that miR-181b, miR-451, miR-497 and miR-200bc/429 cluster sensitize the cells to platinuminduced cell death, by down-regulating the expression of $B C L-2$ anti-apoptotic gene, whose overexpression causes drug resistance [74-76]. Overexpression of miR-451 inhibited growth and enhanced the sensitivity of A549 lung adenocarcinoma cells to cisplatin, by inducing apoptosis through inhibition of Akt signaling pathway, while increased expression of miR-200bc/429 cluster reduced BCL-2 and XIAP (Xlinked inhibitor of apoptosis protein) protein expression levels [77]. Finally, Gao and collaborators reported that miR-21 might predict adjuvant platinum-based chemotherapy response in NSCLC patients, because its overexpression induces resistance to platinum in A549 cells, by reducing PTEN expression and increasing BCL-2 expression [78].
Apoptosis pathways can also be the primary targets of anticancer drugs, such as in the case of the Apo2L/tumor necrosis factor (TNF)-related apoptosis-inducing ligand (TRAIL), a member of the TNF family that induces programmed cell death in a variety of cancers [79]. However, a significant proportion of tumors are resistant to TRAILinduced apoptosis. A recent study reported that miR-24 directly down-regulates XIAP expression by targeting its 3 ' UTR and inducing sensitivity to TRAIL in TRAIL-resistant lung cells [80]. Furthermore, Garofalo and collaborators performed a genome-wide expression study of miRNAs in NSCLC cell lines with differential TRAIL-sensitivity and showed the key role of miR-221 and -222 by regulating p27kip1 expression and TRAIL-induced caspase machinery [81]. In particular, the expression of miR-110, miR-221, miR-222 and miR-125b was up-regulated from 5- to 8-fold in TRAIL-resistant cells and down-regulated in TRAILsensitive cells [3]. Ectopic overexpression of miR-110, 
miR-221 and miR-222 induced resistance in H460 sensitive cells, while Calu-1 resistant cells transfected with anti-miR221 or anti-miR-222 became sensitive to TRAIL [54]. MiR221 and miR-222 promote tumorigenesis and metastasis in lung cancer, by down-regulating PTEN and TIMP3. Moreover, a common genetic aberration detected in lung cancer progression is activation of MET oncogene signaling [82] and miR-221 and miR-222 expression levels are regulated by MET through c-Jun transcription factor and JNK activation [83]. Similarly, miR-130a induces TRAIL sensitivity, by targeting MET and down-regulating miR-221 and miR-222 [84].

Finally, Nasser and collaborators reported that ectopic expression of miR-1 reduces cell proliferation and enhance the induction of apoptosis by doxorubicin in A549 cells, by promoting the activation of effector caspases and degradation of the anti-apoptotic member of BCL-2 family Mcl-1 [85], whereas another study demonstrated that miR-212 negatively modulates the expression of a death effector domain family member, called PED, which is an anti-apoptotic factor regulating cellular sensitivity towards TRAIL [86].

These results, summarized in Table 1, suggest that therapeutic intervention, involving the use of microRNAs, should not only sensitize tumor cells to drug-induced apoptosis but also inhibit survival, proliferation, and metastatic properties of lung cancer.

\subsection{MiRNAs Involved in Chemoresistance through Cell Cycle Regulation}

MiRNAs can be associated with cell cycle deregulation that might also influence resistance to anticancer agents (Table 1). Some miRNAs may modulate the chemoresistance by targeting E2F transcription factor family that is involved in the regulation of cell cycle. Recently, Donzelli and collaborators showed that miR-128-2 expression, induced by a mutant p53 protein, inhibits apoptosis and causes increased resistance to doxorubicin, cisplatin and 5-fluorouracil in NSCLC cells. MiR-128-2, by targeting E2F5, inhibits its repressive activity on transcription of $\mathrm{p} 21^{\text {waf1 }}$, which exerts an anti-apoptotic effect by reducing pro-caspase-3 cleavage [87]. Additionally, miR-330 expression was correlated with resistance to gemcitabine in various lung cancer cell lines, since gemcitabine-sensitive cells showed a lower expression of miR-330 than gemcitabine-resistant cells. E2F1 is an indirect target of miR-330, because miR-330 overexpression reduced E2F1-mediated Akt phosphorylation [88]. Moreover, miR-330 expression was inversely correlated with the mRNA expression of deoxycytidine kinase (dCK), supporting a role of miR-330 in post-transcriptional regulation of $\mathrm{dCK}$, which is critical for phosphorylation of deoxynucleoside analogs, such as gemcitabine and cytarabine [89]. MiR$200 \mathrm{~b}$ is another miRNA correlated to E2F transcription factor family. Ectopic miR-200b expression reduced chemoresistance to docetaxel by inhibition of cell proliferation, induction of apoptosis, and arrest of cell cycle at G2/M [66]. MiR-200b directly targets $E 2 F 3$, which usually acts as a transcriptional activator by increasing cellular proliferation through the G1/S transition [90-92].

MiR-100 had a significantly lower expression in docetaxel-resistant SPC-A1/DTX cells compared with parental
SPC-A1 cells. MiR-100 could induce sensitivity to docetaxel, by targeting $P l k 1$ [93], which plays a key role in cell cycle progression through various mitosis stages, as directly promotes entry in mitosis by activating Cdc25C [94] and Cdk1/Cyclin B complex [95]. Furthermore, as reported above, overexpression of miR-337-3p confers sensitivity to paclitaxel, inducing G2/M arrest [70].

\subsection{MiRNAs Involved in Chemoresistance through DNA Damage Repair Mechanisms}

Some miRNAs may modulate the chemoresistance through regulation of DNA damage repair (DDR) mechanisms (Table 1). For instance, the expression of excision repair cross-complementation group 1 (ERCC1) gene, involved in NER, was correlated with resistance to platinumderived drugs. In 2011, Wang and collaborators reported the aberrations of 14 miRNAs in the A549/DDP cisplatinresistant cell lines in comparison with the parental A549 cell lines. Among these, miR-138 could affect the development of resistance to cisplatin in NSCLC, by negatively regulating ERCC1 [96]. Furthermore, glutathione S-transferase P1 (GSTP1) plays a key role in protecting cells from carcinogens and cytotoxic agents. MiR-513a-3p could therefore increase apoptosis induced by cisplatin in human NSCLC cell lines, by targeting GSTP1 [97]. In addition, miR-630 recently emerged as a novel modulator of response to cisplatin, since its overexpression, not only induced cell cycle arrest, but also counteract early events of the response to DNA damage, such as the phosphorylation of ATM kinase and of the ATM substrates histone H2AX and p53 [54], which affect response to DNA damage.

\section{MiRNAS AND RESISTANCE TO TARGETED THERAPY IN NSCLC}

Drugs that target the epidermal growth factor receptor (EGFR) are now major actors in the treatment of NSCLC. These drugs allowed us to better understand the molecular biology of NSCLC, including the discovery that activating mutations in EGFR correlated to a better response to antiEGFR treatments. In fact, a strong association between activating mutations in the EGFR tyrosine kinase domain and the response to the EGFR tyrosine kinase inhibitors (TKIs) gefitinib and erlotinib has been demonstrated in many clinical trials. Although EGFR-mutant NSCLCs initially respond to anti-EGFR drugs, most of these cancers ultimately become resistant. The main mechanisms of acquired resistance to these drugs include secondary mutations in EGFR, such as the gatekeeper T790M mutation, detected in approximatively $50 \%$ of resistant cases; and amplification of the MET oncogene [98], observed in 5-20\% of resistant cases [99]. This resistance can be overcome by EGFR inhibition by miR-7, which targets three sites in the 3'-untranslated region of EGFR mRNA [100]. Recent evidence showed that several miRNAs can be involved in resistance to different drugs targeting EGFR (Table 2). Preliminary studies in NSCLC cell lines demonstrated that increased expression of miR-21, miR-23a, miR-23b, and miR-29 are associated with resistance in three sunitinib-resistant variants of $\mathrm{H} 1703$ cells [101, 102], while decreased miR-424 levels are associated with increased resistance to erlotinib and vandetanib [103]. Recently, it has been reported that the HCC827/GR, gefitinib 
Table 2. MicroRNAs involved in resistance to novel targeted agents.

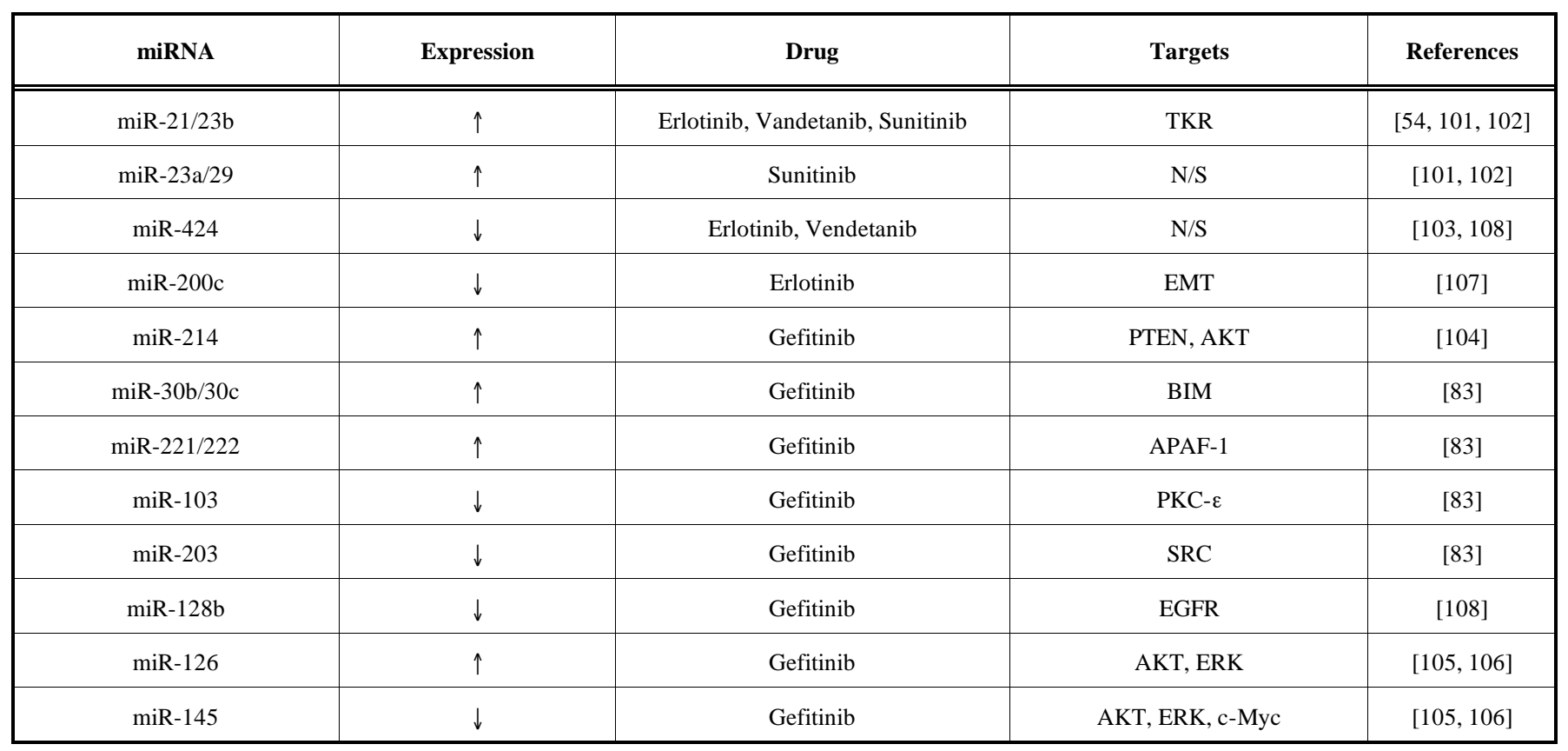

$\uparrow$ Up-regulated and $\downarrow$ down-regulated microRNAs in drug resistance. $\mathrm{N} / \mathrm{S}=$ target not specified.

resistant cell line, showed a relevant up-regulation of miR214 and the knockdown of miR-214 altered the expression levels of PTEN and p-Akt, and re-sensitized HCC827/GR to gefitinib [104]. The activation of both p-Akt and ERK can be regulated by miR-126, whose overexpression inhibits the cell proliferation and significantly enhances the cytotoxicity induced by gefitinib in H460 and A549 cells. In addition, miR126 is involved in cell adhesion, migration, invasion, angiogenesis, and regulation of VEGF-A [105]. Also, miR-145 down-regulation is associated with resistance to gefitinib, whereas its overexpression inhibits the cell proliferation by targeting c-Myc [106]. In 2012, Bryant and collaborators reported that the expression levels of 13 miRNAs might predict response to erlotinib in cancer cell lines, and discriminates primary tumors from metastatic lesions. These miRNAs, in particular miR-140-3p, miR-628-5p, miR-518f, miR-636, miR-301a, miR-34c, miR-224, miR-197, miR-205, miR135b, miR-200b, miR-200c, and miR-141, regulate proteins that are potentially involved in epithelial-to-mesenchymal transition (EMT). Interestingly, treatment with TGF $\beta 1$ modulated the expression of these miRNAs and EMT proteins and, for this reason, they hypothesized that the tumor microenvironment elicits TGF $\beta 1$ and promotes a miRNA expression pattern that induces resistance to anti-EGFR and favors the induction of EMT, invasion, and metastasis in lung cancer cells [107]. A pivotal study reported that miR-30b, miR30c, miR-221 and miR-222 are regulated by both EGF and MET receptors, while miR-103 and miR-203 are modulated only by MET. These miRNAs have important roles in gefitinib-induced apoptosis and EMT of NSCLC cells. In fact, treatment with gefitinib causes apoptosis through the downregulation of miR-30b, miR-30c, miR-221 and miR-222 and the consequent overexpression of APAF-1 and BIM in gefitinib-sensitive cells. Conversely, gefitinib did not affect miR30b, miR-30c, miR-221 and miR-222 expression in gefit- inib-resistant cells as a result of MET overexpression. Interestingly, gefitinib-resistance was overcome through MET inhibitors, which down-regulated these microRNAs and sensitized NSCLCs to gefitinib [83].

To date, little is known about the possible correlation of miRNAs expression with NSCLC patients outcome after treatment with EGFR inhibitors. Weiss and collaborators reported that miR-128b is a direct regulator of EGFR and loss of heterozygosity of this miRNA is frequently found in NSCLC patients, and is positively correlated with clinical response and survival after gefitinib treatment [108]. Another study by Seike and collaborators reported a significant association between the EGFR mutation status and miR-21 expression, but these results were not validated in a study on a larger number of NSCLC tissues [109]. Table 2 summarizes miRNAs involved in resistance to targeted therapy in NSCLC.

\section{CONCLUSIONS AND FUTURE PERSPECTIVES}

Resistance to conventional chemotherapy can be induced by several mechanisms which are partially overlapping with those involved in resistance to novel targeted agents, including drug inactivation, modifications of drug targets, reduced drug uptake and increased drug elimination. However, recent data showed that drug resistance mechanisms might also be regulated by alterations in miRNA expression. Today, several in vitro studies are ongoing to investigate molecular mechanisms underlying the role of microRNAs in NSCLC resistance, in order to exploit miRNAs as therapeutic targets. The identification of new possible molecular mechanisms of resistance to conventional chemotherapy and novel targeted therapies could represent an important tool to select NSCLC patients who could have benefit from treatment. This research provides multidisciplinary approaches, by promoting 
the interaction between basic research and clinical research, and integrating significantly the fields of oncology and molecular biology.

In conclusion, recent studies showed that miRNAs may play important roles in the regulation of anti-cancer drug resistance, by regulating several signaling pathways, including apoptosis, cell cycle, proliferation and DNA damage repair, as well as the EGFR pathway. Hopefully, in the near future, the expression profiles of specific miRNAs could provide new information about resistance of individual tumors to different treatments before starting therapy, while modulation of the expression of specific miRNAs during treatment might offer a new tool for the prediction of acquired resistance. Moreover, specific modulation of miRNA activity could improve the activity of conventional chemotherapy and novel targeted agents in NSCLC patients. Therefore, identification of candidate miRNAs affecting drug resistance and analysis of their molecular mechanisms could be useful for designing novel and targeted miRNA-based therapeutic strategies to improve the clinical outcome of NSCLC patients.

\section{CONFLICT OF INTEREST}

The authors confirm that this article content has no conflicts of interest.

\section{ACKNOWLEDGEMENTS}

Declared none.

\section{REFERENCES}

[1] Siegel, R.; Naishadham, D.; Jemal, A. Cancer statistics, 2012. CA Cancer J. Clin., 2012, 62(1), 10-29.

[2] Langer, C.J.; Besse, B.; Gualberto, A.; Brambilla, E.; Soria, J.C. The evolving role of histology in the management of advanced non-small-cell lung cancer. J. Clin. Oncol., 2010, 28(36), 53115320 .

[3] Giovannetti, E.; Erozenci, A.; Smit, J.; Danesi, R.; Peters, G. J. Molecular mechanisms underlying the role of microRNAs (miRNAs) in anticancer drug resistance and implications for clinical practice. Crit. Rev. Oncol. Hematol., 2012, 81(2), 103-22.

[4] Ambudkar, S.V.; Dey, S.; Hrycyna, C.A.; Ramachandra, M.; Pastan, I.; Gottesman, M.M. Biochemical, cellular, and pharmacological aspects of the multidrug transporter. Annu. Rev. Pharmacol. Toxicol., 1999, 39, 361-398.

[5] Rodrigues, A.S.; Dinis, J.; Gromicho, M.; Martins, C.; Laires, A.; Rueff, J. Genomics and cancer drug resistance. Curr. Pharm. Biotechnol., 2012, 13(5), 651-673.

[6] Longley, D.B.; Johnston, P.G. Molecular mechanisms of drug resistance. J. Pathol., 2005, 205(2), 275-92.

[7] Gottesman, M.M.; Fojo, T.; Bates, S.E. Multidrug resistance in cancer: role of ATP-dependent transporters. Nat. Rev. Cancer, 2002, 2(1), 48-58.

[8] Townsend, D.M.; Tew, K.D. The role of glutathione-S-transferase in anti-cancer drug resistance. Oncogene, 2003, 22(47), 7369-7375.

[9] Johnston, P.G.; Drake, J.C.; Trepel, J.; Allegra, C.J. Immunological Quantitation of Thymidylate Synthase Using the MonoclonalAntibody Ts 106 in 5-Fluorouracil-Sensitive and 5-FluorouracilResistant Human Cancer Cell-Lines. Cancer Res., 1992, 52(16), 4306-4312.

[10] Galvani, E.; Peters, G.J.; Giovannetti, E. EGF receptor-targeted therapy in non-small-cell lung cancer: role of germline polymorphisms in outcome and toxicity. Future Oncol., 2012, 8(8), 1015-1029.
[11] Rosell, R.; Lord, R.V.; Taron, M.; Reguart, N. DNA repair and cisplatin resistance in non-small-cell lung cancer. Lung Cancer, 2002, 38(3), 217-227.

[12] Lord, R.V.; Brabender, J.; Gandara, D.; Alberola, V.; Camps, C. Domine, M.; Cardenal, F.; Sanchez, J.M.; Gumerlock, P.H.; Taron, M.; Sanchez, J.J.; Danenberg, K.D.; Danenberg, P.V.; Rosell, R. Low ERCC1 expression correlates with prolonged survival after cisplatin plus gemcitabine chemotherapy in non-small cell lung cancer. Clin. Cancer Res., 2002, 8(7), 2286-2291.

[13] Liu, A.; Yoshioka, K.; Salerno, V.; Hsieh, P. The mismatch repairmediated cell cycle checkpoint response to fluorodeoxyuridine. $J$. Cell Biochem., 2008, 105(1), 245-254.

[14] Adhikari, S.; Choudhury, S.; Mitra, P.S.; Dubash, J.J.; Sajankila, S.P.; Roy, R. Targeting base excision repair for chemosensitization. Anticancer Agents Med. Chem., 2008, 8(4), 351-357.

[15] Polischouk, A.G.; Holgersson, A.; Zong, D.; Stenerlow, B.; Karlsson, H.L.; Moller, L.; Viktorsson, K.; Lewensohn, R. The antipsychotic drug trifluoperazine inhibits DNA repair and sensitizes non small cell lung carcinoma cells to DNA doublestrand break induced cell death. Mol. Cancer Ther., 2007, 6(8), 2303-2309.

[16] Hansen, L.T.; Lundin, C.; Spang-Thomsen, M.; Petersen, L.N.; Helleday, T. The role of RAD51 in etoposide (VP16) resistance in small cell lung cancer. Int. J. Cancer, 2003, 105(4), 472-429.

[17] Bunz, F. Cell death and cancer therapy. Curr. Opin. Pharmacol., 2001, 1(4), 337-341.

[18] Fojo, T. Multiple paths to a drug resistance phenotype: mutations, translocations, deletions and amplification of coding genes or promoter regions, epigenetic changes and microRNAs. Drug Resist. Updat., 2007, 10(1-2), 59-67.

[19] Lagos-Quintana, M.; Rauhut, R.; Lendeckel, W.; Tuschl, T. Identification of novel genes coding for small expressed RNAs. Science, 2001, 294(5543), 853-858.

[20] Bartel, D.P. MicroRNAs: genomics, biogenesis, mechanism, and function. Cell, 2004, 116(2), 281-297.

[21] Lee, R.C.; Feinbaum, R.L.; Ambros, V. The C. elegans heterochronic gene lin-4 encodes small RNAs with antisense complementarity to lin-14. Cell, 1993, 75(5), 843-54.

[22] Corsini, L.R.; Bronte, G.; Terrasi, M.; Amodeo, V.; Fanale, D.; Fiorentino, E.; Cicero, G.; Bazan, V.; Russo, A. The role of microRNAs in cancer: Diagnostic and prognostic biomarkers and targets of therapies. Expert Opin. Ther. Targets, 2012, 16(Suppl 2), S103-109.

[23] Caruso, S.; Bazan, V.; Rolfo, C.; Insalaco, L.; Fanale, D.; Bronte, G.; Corsini, L.R.; Rizzo, S.; Cicero, G.; Russo, A. MicroRNAs in colorectal cancer stem cells: new regulators of cancer stemness? Oncogenesis, 2012, 1, e32.

[24] Lee, Y.; Kim, M.; Han, J.; Yeom, K.H.; Lee, S.; Baek, S.H.; Kim, V.N. MicroRNA genes are transcribed by RNA polymerase II. EMBO J., 2004, 23(20), 4051-4060.

[25] Borchert, G.M.; Lanier, W.; Davidson, B.L. RNA polymerase III transcribes human microRNAs. Nat. Struct. Mol. Biol., 2006, 13(12), 1097-1101.

[26] Gregory, R.I.; Yan, K.P.; Amuthan, G.; Chendrimada, T.; Doratotaj, B.; Cooch, N.; Shiekhattar, R. The Microprocessor complex mediates the genesis of microRNAs. Nature, 2004, 432(7014), 235-240.

[27] Kim, V.N. MicroRNA biogenesis: Coordinated cropping and dicing. Nat. Rev. Mol. Cell Biol., 2005, 6(5), 376-85.

[28] Li, M.; Marin-Muller, C.; Bharadwaj, U.; Chow, K.H.; Yao, Q.; Chen, C. MicroRNAs: Control and loss of control in human physiology and disease. World J. Surg., 2009, 33(4), 667-84.

[29] Calin, G.A.; Dumitru, C.D.; Shimizu, M.; Bichi, R.; Zupo, S.; Noch, E.; Aldler, H.; Rattan, S.; Keating, M.; Rai, K.; Rassenti, L.; Kipps, T.; Negrini, M.; Bullrich, F.; Croce, C.M. Frequent deletions and down-regulation of micro- RNA genes miR15 and miR16 at 13q14 in chronic lymphocytic leukemia. Proc. Natl. Acad. Sci. USA, 2002, 99(24), 15524-15529.

[30] Visone, R.; Croce, C.M., MiRNAs and cancer. Am. J. Pathol., 2009, 174(4), 1131-1138.

[31] Hatley, M.E.; Patrick, D.M.; Garcia, M.R.; Richardson, J.A.; Bassel-Duby, R.; van Rooij, E.; Olson, E.N. Modulation of K-Rasdependent lung tumorigenesis by MicroRNA-21. Cancer Cell, 2010, 18(3), 282-93 
[32] Johnson, S. M.; Grosshans, H.; Shingara, J.; Byrom, M.; Jarvis, R.; Cheng, A.; Labourier, E.; Reinert, K.L.; Brown, D.; Slack, F.J. RAS is regulated by the let-7 MicroRNA family. Cell, 2005, 120(5), 635-647.

[33] Yanaihara, N.; Caplen, N.; Bowman, E.; Seike, M.; Kumamoto, K.; Yi, M.; Stephens, R.M.; Okamoto, A.; Yokota, J.; Tanaka, T.; Calin, G.A.; Liu, C.G.; Croce, C.M.; Harris, C.C. Unique microRNA molecular profiles in lung cancer diagnosis and prognosis. Cancer Cell, 2006, 9(3), 189-98.

[34] Yu, S.L.; Chen, H.Y.; Chang, G.C.; Chen, C.Y.; Chen, H.W.; Singh, S.; Cheng, C.L.; Yu, C.J.; Lee, Y.C.; Chen, H.S.; Su, T.J.; Chiang, C.C.; Li, H.N.; Hong, Q.S.; Su, H.Y.; Chen, C.C.; Chen, W.J.; Liu, C.C.; Chan, W.K.; Li, K.C.; Chen, J.J.; Yang, P.C. MicroRNA signature predicts survival and relapse in lung cancer. Cancer Cell, 2008, 13(1), 48-57.

[35] Broxterman, H.J.; Gotink, K.J.; Verheul, H. M. Understanding the causes of multidrug resistance in cancer: a comparison of doxorubicin and sunitinib. Drug Resist. Updat., 2009, 12(4-5), 114126.

[36] Blower, P.E.; Chung, J.H.; Verducci, J.S.; Lin, S.; Park, J.K.; Dai, Z.; Liu, C.G.; Schmittgen, T.D.; Reinhold, W.C.; Croce, C.M.; Weinstein, J.N.; Sadee, W. MicroRNAs modulate the chemosensitivity of tumor cells. Mol. Cancer Ther., 2008, 7(1), 1-9.

[37] Wu, X.; Xiao, H. miRNAs modulate the drug response of tumor cells. Sci. China C Life Sci., 2009, 52(9), 797-801.

[38] Bertino, J.R.; Banerjee, D.; Mishra, P.J. Pharmacogenomics of microRNA: a miRSNP towards individualized therapy. Pharmacogenomics, 2007, 8(12), 1625-1627.

[39] Orom, U.A.; Kauppinen, S.; Lund, A.H. LNA-modified oligonucleotides mediate specific inhibition of microRNA function. Gene, 2006, 372, 137-41.

[40] Hutvagner, G.; Simard, M.J.; Mello, C.C.; Zamore, P.D. Sequencespecific inhibition of small RNA function. PLoS Biol., 2004, 2(4), E98.

[41] Meister, G.; Landthaler, M.; Dorsett, Y.; Tuschl, T. Sequencespecific inhibition of microRNA- and siRNA-induced RNA silencing. RNA, 2004, 10(3), 544-50.

[42] Krutzfeldt, J.; Rajewsky, N.; Braich, R.; Rajeev, K.G.; Tuschl, T.; Manoharan, M.; Stoffel, M. Silencing of microRNAs in vivo with 'antagomirs'. Nature, 2005, 438(7068), 685-9.

[43] Zheng, T.; Wang, J.; Chen, X.; Liu, L. Role of microRNA in anticancer drug resistance. Int. J. Cancer, 2010, 126(1), 2-10.

[44] Wellner, U.; Schubert, J.; Burk, U.C.; Schmalhofer, O.; Zhu, F.; Sonntag, A.; Waldvogel, B.; Vannier, C.; Darling, D.; zur Hausen, A.; Brunton, V.G.; Morton, J.; Sansom, O.; Schuler, J.; Stemmler, M.P.; Herzberger, C.; Hopt, U.; Keck, T.; Brabletz, S.; Brabletz, T. The EMT-activator ZEB1 promotes tumorigenicity by repressing stemness-inhibiting microRNAs. Nat. Cell Biol., 2009, 11(12), 1487-1495.

[45] Shimono, Y.; Zabala, M.; Cho, R.W.; Lobo, N.; Dalerba, P.; Qian, D.; Diehn, M.; Liu, H.; Panula, S.P.; Chiao, E.; Dirbas, F.M.; Somlo, G.; Pera, R.A.; Lao, K.; Clarke, M.F. Downregulation of miRNA-200c links breast cancer stem cells with normal stem cells. Cell, 2009, 138(3), 592-603.

[46] Peter, M.E. Regulating cancer stem cells the miR way. Cell Stem Cell, 2010, 6(1), 4-6.

[47] Wang, Z.; Li, Y.; Ahmad, A.; Azmi, A.S.; Kong, D.; Banerjee, S.; Sarkar, F.H. Targeting miRNAs involved in cancer stem cell and EMT regulation: An emerging concept in overcoming drug resistance. Drug Resist. Updat., 2010, 13(4-5), 109-118.

[48] Johnson, C.D.; Esquela-Kerscher, A.; Stefani, G.; Byrom, M.; Kelnar, K.; Ovcharenko, D.; Wilson, M.; Wang, X.; Shelton, J.; Shingara, J.; Chin, L.; Brown, D.; Slack, F.J. The let-7 microRNA represses cell proliferation pathways in human cells. Cancer Res., 2007, 67(16), 7713-7722.

[49] Fanale, D.; Caruso, S.; Bazan, V.; Bronte, G.; Di Piazza, F.; Rolfo, C.; Li Muli, M.; Cicero, G.; Russo, A. MicroRNAs in Colorectal Cancer Drug Resistance: Shooters become Targets. $J$. Carcinogenes. Mutagenes., 2013,04(01).

[50] Tsang, W.P.; Kwok, T.T. Epigallocatechin gallate up-regulation of miR-16 and induction of apoptosis in human cancer cells. J. Nutr. Biochem., 2010, 21(2), 140-146.

[51] Sun, M.; Estrov, Z.; Ji, Y.; Coombes, K.R.; Harris, D.H.; Kurzrock, R. Curcumin (diferuloylmethane) alters the expression profiles of
microRNAs in human pancreatic cancer cells. Mol. Cancer Ther., 2008, 7(3), 464-473.

[52] Melkamu, T.; Zhang, X.; Tan, J.; Zeng, Y.; Kassie, F. Alteration of microRNA expression in vinyl carbamate-induced mouse lung tumors and modulation by the chemopreventive agent indole-3carbinol. Carcinogenesis, 2010, 31(2), 252-258.

[53] Li, Y.; Kong, D.; Wang, Z.; Sarkar, F.H. Regulation of microRNAs by natural agents: an emerging field in chemoprevention and chemotherapy research. Pharm. Res., 2010, 27(6), 1027-1041.

[54] Sarkar, F.H.; Li, Y.; Wang, Z.; Kong, D.; Ali, S. Implication of microRNAs in drug resistance for designing novel cancer therapy. Drug Resist. Updat., 2010, 13(3), 57-66.

[55] Buscaglia, L.E.; Li, Y. Apoptosis and the target genes of microRNA-21. Chin. J. Cancer, 2011, 30(6), 371-380.

[56] Park, S.M.; Peter, M.E. microRNAs and death receptors. Cytokine Growth Factor Rev., 2008, 19(3-4), 303-311.

[57] Schulze-Bergkamen, H.; Krammer, P.H. Apoptosis in cancer-implications for therapy. Semin. Oncol., 2004, 31(1), 90-119.

[58] Kanakkanthara, A.; Miller, J.H. MicroRNAs: Novel mediators of resistance to microtubule-targeting agents. Cancer Treatment Rev., 2013, 39(2), 161-170.

[59] Di Cristofano, A.; Pandolfi, P.P. The multiple roles of PTEN in tumor suppression. Cell, 2000, 100(4), 387-390.

[60] Li, C.; Hashimi, S.M.; Good, D.A.; Cao, S.; Duan, W.; Plummer, P.N.; Mellick, A.S.; Wei, M.Q. Apoptosis and microRNA aberrations in cancer. Clin. Exp. Pharmacol. Physiol., 2012, 39(8), 739-746.

[61] Bussing, I.; Slack, F.J.; Grosshans, H. let-7 microRNAs in development, stem cells and cancer. Trends Mol. Med., 2008 14(9), 400-409.

[62] Yvon, A.M.; Wadsworth, P.; Jordan, M.A. Taxol suppresses dynamics of individual microtubules in living human tumor cells. Mol. Biol. Cell, 1999, 10(4), 947-959.

[63] Wang, T.H.; Wang, H.S.; Soong, Y.K. Paclitaxel-induced cell death: Where the cell cycle and apoptosis come together. Cancer, 2000, 88(11), 2619-2628.

[64] Yu, H. Regulation of APC-Cdc20 by the spindle checkpoint. Curr. Opin. Cell Biol., 2002, 14(6), 706-714.

[65] Rui, W.; Bing, F.; Hai-Zhu, S.; Wei, D.; Long-Bang, C. Identification of microRNA profiles in docetaxel-resistant human non-small cell lung carcinoma cells (SPC-A1). J. Cell Mol. Med., 2010, 14(1-2), 206-214.

[66] Feng, B.; Wang, R.; Song, H.Z.; Chen, L.B. MicroRNA-200b reverses chemoresistance of docetaxel-resistant human lung adenocarcinoma cells by targeting E2F3. Cancer, 2012, 118(13), 3365-3376.

[67] Feng, S.; Cong, S.; Zhang, X.; Bao, X.; Wang, W.; Li, H.; Wang, Z.; Wang, G.; Xu, J.; Du, B.; Qu, D.; Xiong, W.; Yin, M.; Ren, X.; Wang, F.; He, J.; Zhang, B. MicroRNA-192 targeting retinoblastoma 1 inhibits cell proliferation and induces cell apoptosis in lung cancer cells. Nucleic Acids Res., 2011, 39(15), 6669-6678

[68] Holleman, A.; Chung, I.; Olsen, R.R.; Kwak, B.; Mizokami, A.; Saijo, N.; Parissenti, A.; Duan, Z.; Voest, E.E.; Zetter, B.R. miR135 a contributes to paclitaxel resistance in tumor cells both in vitro and in vivo. Oncogene, 2011, 30(43), 4386-4398.

[69] Catuogno, S.; Cerchia, L.; Romano, G.; Pognonec, P.; Condorelli, G.; de Franciscis, V. miR-34c may protect lung cancer cells from paclitaxel-induced apoptosis. Oncogene, 2013, 32(3), 341-351.

[70] Du, L.; Subauste, M.C.; DeSevo, C.; Zhao, Z.; Baker, M.; Borkowski, R.; Schageman, J.J.; Greer, R.; Yang, C.R.; Suraokar, M.; Wistuba, II; Gazdar, A.F.; Minna, J.D.; Pertsemlidis, A. miR$337-3 p$ and its targets STAT3 and RAP1A modulate taxane sensitivity in non-small cell lung cancers. PLoS One, 2012, 7(6), e39167.

[71] Klampfer, L. Signal transducers and activators of transcription (STATs): Novel targets of chemopreventive and chemotherapeutic drugs. Curr. Cancer Drug Targets, 2006, 6(2), 107-121.

[72] Galluzzi, L.; Morselli, E.; Vitale, I.; Kepp, O.; Senovilla, L.; Criollo, A.; Servant, N.; Paccard, C.; Hupe, P.; Robert, T.; Ripoche, H.; Lazar, V.; Harel-Bellan, A.; Dessen, P.; Barillot, E.; Kroemer, G. miR-181a and miR-630 regulate cisplatin-induced cancer cell death. Cancer Res., 2010, 70(5), 1793-1803. 
[73] Zhang, S.; Zhang, C.; Li, Y.; Wang, P.; Yue, Z.; Xie, S. miR-98 regulates cisplatin-induced A549 cell death by inhibiting TP53 pathway. Biomed. Pharmacother., 2011, 65(6), 436-442.

[74] Zhu, W.; Shan, X.; Wang, T.; Shu, Y.; Liu, P. miR-181b modulates multidrug resistance by targeting BCL2 in human cancer cell lines. Int. J. Cancer, 2010, 127(11), 2520-2529.

[75] Bian, H.B.; Pan, X.; Yang, J.S.; Wang, Z.X.; De, W. Upregulation of microRNA-451 increases cisplatin sensitivity of non-small cell lung cancer cell line (A549). J. Exp. Clin. Cancer Res., 2011, 30, 20.

[76] Zhu, W.; Zhu, D.; Lu, S.; Wang, T.; Wang, J.; Jiang, B.; Shu, Y.; Liu, P. miR-497 modulates multidrug resistance of human cancer cell lines by targeting BCL2. Med. Oncol., 2012, 29(1), 384-391.

[77] Zhu, W.; Xu, H.; Zhu, D.; Zhi, H.; Wang, T.; Wang, J.; Jiang, B.; Shu, Y.; Liu, P. miR-200bc/429 cluster modulates multidrug resistance of human cancer cell lines by targeting BCL2 and XIAP. Cancer Chemother. Pharmacol., 2012, 69(3), 723-731.

[78] Gao, W.; Lu, X.; Liu, L.; Xu, J.; Feng, D.; Shu, Y. MiRNA-21: a biomarker predictive for platinum-based adjuvant chemotherapy response in patients with non-small cell lung cancer. Cancer Biol. Ther., 2012, 13(5), 330-340.

[79] Schaefer, U.; Voloshanenko, O.; Willen, D.; Walczak, H. TRAIL: a multifunctional cytokine. Front Biosci., 2007, 12, 3813-3824.

[80] Xie, Y.; Tobin, L.A.; Camps, J.; Wangsa, D.; Yang, J.; Rao, M.; Witasp, E.; Awad, K.S.; Yoo, N.; Ried, T.; Kwong, K.F. MicroRNA-24 regulates XIAP to reduce the apoptosis threshold in cancer cells. Oncogene, 2013, 32(19), 2442-2451.

[81] Garofalo, M.; Quintavalle, C.; Di Leva, G.; Zanca, C.; Romano, G.; Taccioli, C.; Liu, C.G.; Croce, C.M.; Condorelli, G. MicroRNA signatures of TRAIL resistance in human non-small cell lung cancer. Oncogene, 2008, 27(27), 3845-3855.

[82] Benedettini, E.; Sholl, L.M.; Peyton, M.; Reilly, J.; Ware, C.; Davis, L.; Vena, N.; Bailey, D.; Yeap, B.Y.; Fiorentino, M.; Ligon, A.H.; Pan, B.S.; Richon, V.; Minna, J.D.; Gazdar, A.F.; Draetta, G.; Bosari, S.; Chirieac, L.R.; Lutterbach, B.; Loda, M. Met activation in non-small cell lung cancer is associated with de novo resistance to EGFR inhibitors and the development of brain metastasis. Am. J. Pathol., 2010, 177(1), 415-423.

[83] Garofalo, M.; Romano, G.; Di Leva, G.; Nuovo, G.; Jeon, Y.J.; Ngankeu, A.; Sun, J.; Lovat, F.; Alder, H.; Condorelli, G.; Engelman, J.A.; Ono, M.; Rho, J.K.; Cascione, L.; Volinia, S.; Nephew, K.P.; Croce, C.M. EGFR and MET receptor tyrosine kinase-altered microRNA expression induces tumorigenesis and gefitinib resistance in lung cancers. Nat. Med., 2012, 18(1), 74-82.

[84] Acunzo, M.; Visone, R.; Romano, G.; Veronese, A.; Lovat, F.; Palmieri, D.; Bottoni, A.; Garofalo, M.; Gasparini, P.; Condorelli, G.; Chiariello, M.; Croce, C.M. miR-130a targets MET and induces TRAIL-sensitivity in NSCLC by downregulating miR-221 and 222. Oncogene, 2012, 31(5), 634-642.

[85] Nasser, M.W.; Datta, J.; Nuovo, G.; Kutay, H.; Motiwala, T.; Majumder, S.; Wang, B.; Suster, S.; Jacob, S.T.; Ghoshal, K. Down-regulation of micro-RNA-1 (miR-1) in lung cancer. Suppression of tumorigenic property of lung cancer cells and their sensitization to doxorubicin-induced apoptosis by miR-1. J. Biol. Chem., 2008, 283(48), 33394-3405.

[86] Incoronato, M.; Garofalo, M.; Urso, L.; Romano, G.; Quintavalle, C.; Zanca, C.; Iaboni, M.; Nuovo, G.; Croce, C.M.; Condorelli, G. miR-212 increases tumor necrosis factor-related apoptosis-inducing ligand sensitivity in non-small cell lung cancer by targeting the antiapoptotic protein PED. Cancer Res., 2010, 70(9), 3638-3646.

[87] Donzelli, S.; Fontemaggi, G.; Fazi, F.; Di Agostino, S.; Padula, F.; Biagioni, F.; Muti, P.; Strano, S.; Blandino, G. MicroRNA-128-2 targets the transcriptional repressor E2F5 enhancing mutant p53 gain of function. Cell Death Differ., 2012, 19(6), 1038-1048.

[88] Hodzic, J.; Giovannetti, E.; Diosdado, B.; Adema, A.D.; Peters, G.J. Regulation of deoxycytidine kinase expression and sensitivity to gemcitabine by micro-RNA 330 and promoter methylation in cancer cells. Nucleosides Nucleotides Nucleic Acids, 2011, 30(12), 1214-1222.

[89] Lee, K.H.; Chen, Y.L.; Yeh, S.D.; Hsiao, M.; Lin, J.T.; Goan, Y.G.; Lu, P.J. MicroRNA-330 acts as tumor suppressor and induces apoptosis of prostate cancer cells through E2F1-mediated suppression of Akt phosphorylation. Oncogene, 2009, 28(38), 3360-3370.
[90] Sharma, N.; Timmers, C.; Trikha, P.; Saavedra, H.I.; Obery, A.; Leone, G. Control of the p53-p21CIP1 Axis by E2f1, E2f2, and E2f3 is essential for G1/S progression and cellular transformation. J. Biol. Chem., 2006, 281(47), 36124-36131.

[91] Wu, L.; Timmers, C.; Maiti, B.; Saavedra, H.I.; Sang, L.; Chong, G.T.; Nuckolls, F.; Giangrande, P.; Wright, F.A.; Field, S.J.; Greenberg, M.E.; Orkin, S.; Nevins, J.R.; Robinson, M.L.; Leone, G. The E2F1-3 transcription factors are essential for cellular proliferation. Nature, 2001, 414(6862), 457-462.

[92] Cooper, C.S.; Nicholson, A.G.; Foster, C.; Dodson, A.; Edwards, S.; Fletcher, A.; Roe, T.; Clark, J.; Joshi, A.; Norman, A.; Feber, A.; Lin, D.; Gao, Y.; Shipley, J.; Cheng, S.J. Nuclear overexpression of the E2F3 transcription factor in human lung cancer. Lung Cancer, 2006, 54(2), 155-162.

[93] Feng, B.; Wang, R.; Chen, L.B. MiR-100 resensitizes docetaxelresistant human lung adenocarcinoma cells (SPC-A1) to docetaxel by targeting Plk1. Cancer Lett., 2012, 317(2), 184-191.

[94] Toyoshima-Morimoto, F.; Taniguchi, E.; Nishida, E. Plk1 promotes nuclear translocation of human $\mathrm{Cdc} 25 \mathrm{C}$ during prophase. EMBO Rep., 2002, 3(4), 341-348.

[95] Toyoshima-Morimoto, F.; Taniguchi, E.; Shinya, N.; Iwamatsu, A.; Nishida, E. Polo-like kinase 1 phosphorylates cyclin B1 and targets it to the nucleus during prophase. Nature, 2001, 410(6825), 215220.

[96] Wang, Q.; Zhong, M.; Liu, W.; Li, J.; Huang, J.; Zheng, L. Alterations of microRNAs in cisplatin-resistant human non-small cell lung cancer cells (A549/DDP). Exp. Lung Res., 2011, 37(7), 427-434.

[97] Zhang, X.; Zhu, J.; Xing, R.; Tie, Y.; Fu, H.; Zheng, X.; Yu, B. miR-513a-3p sensitizes human lung adenocarcinoma cells to chemotherapy by targeting GSTP1. Lung Cancer, 2012, 77(3), 488494.

[98] Takezawa, K.; Okamoto, I.; Tanizaki, J.; Kuwata, K.; Yamaguchi, H.; Fukuoka, M.; Nishio, K.; Nakagawa, K. Enhanced anticancer effect of the combination of BIBW2992 and thymidylate synthasetargeted agents in non-small cell lung cancer with the T790M mutation of epidermal growth factor receptor. Mol. Cancer Ther., 2010, 9(6), 1647-1656.

[99] Engelman, J.A.; Zejnullahu, K.; Mitsudomi, T.; Song, Y.; Hyland, C.; Park, J.O.; Lindeman, N.; Gale, C.M.; Zhao, X.; Christensen, J.; Kosaka, T.; Holmes, A.J.; Rogers, A.M.; Cappuzzo, F.; Mok, T.; Lee, C.; Johnson, B.E.; Cantley, L.C.; Janne, P.A. MET amplification leads to gefitinib resistance in lung cancer by activating ERBB3 signaling. Science, 2007, 316(5827), 1039-1043.

[100] Rai, K.; Takigawa, N.; Ito, S.; Kashihara, H.; Ichihara, E.; Yasuda, T.; Shimizu, K.; Tanimoto, M.; Kiura, K. Liposomal delivery of MicroRNA-7-expressing plasmid overcomes epidermal growth factor receptor tyrosine kinase inhibitor-resistance in lung cancer cells. Mol. Cancer Ther., 2011, 10(9), 1720-1727.

[101] Weiss, G.J.; Nelson, K.M.; Edwards, D.K.; Boisvert, S.P.; Sima, C. MicroRNA biomarkers associated with vandetanib, sunitinib, and/or erlotinib resistance. J. Thorac. Oncol., 2010, 5(6), S240S241.

[102] Nelson, K.; Sima, C.; Edwards, D.K.; Weiss, G.J. microRNA biomarkers associated with sunitinib-resistance in non-small cell lung cancer. Cancer Res., 2010, 70(8).

[103] Allen, K.E.; Weiss, G.J. Resistance may not be futile: microRNA biomarkers for chemoresistance and potential therapeutics. Mol. Cancer Ther., 2010, 9(12), 3126-3136.

[104] Wang, Y.S.; Wang, Y.H.; Xia, H.P.; Zhou, S.W.; Schmid-Bindert, G.; Zhou, C.C. MicroRNA-214 regulates the acquired resistance to gefitinib via the PTEN/AKT pathway in EGFR-mutant cell lines. Asian Pac. J. Cancer Prev., 2012, 13(1), 255-260.

[105] Donnem, T.; Lonvik, K.; Eklo, K.; Berg, T.; Sorbye, S.W.; AlShibli, K.; Al-Saad, S.; Andersen, S.; Stenvold, H.; Bremnes, R.M.; Busund, L.T. Independent and tissue-specific prognostic impact of miR-126 in nonsmall cell lung cancer: coexpression with vascular endothelial growth factor-A predicts poor survival. Cancer, 2011, 117(14), 3193-3200.

[106] Zhong, M.; Ma, X.; Sun, C.; Chen, L. MicroRNAs reduce tumor growth and contribute to enhance cytotoxicity induced by gefitinib in non-small cell lung cancer. Chem. Biol. Interact., 2010, 184(3), $431-438$. 
[107] Bryant, J.L.; Britson, J.; Balko, J.M.; Willian, M.; Timmons, R.; Frolov, A.; Black, E.P. A microRNA gene expression signature predicts response to erlotinib in epithelial cancer cell lines and targets EMT. Br. J. Cancer, 2012, 106(1), 148-156.

[108] Weiss, G.J.; Bemis, L.T.; Nakajima, E.; Sugita, M.; Birks, D.K.; Robinson, W.A.; Varella-Garcia, M.; Bunn, P.A., Jr.; Haney, J.; Helfrich, B.A.; Kato, H.; Hirsch, F.R.; Franklin, W.A. EGFR regulation by microRNA in lung cancer: Correlation with clinical response and survival to gefitinib and EGFR expression in cell lines. Ann. Oncol., 2008, 19(6), 1053-1059.

[109] Seike, M.; Goto, A.; Okano, T.; Bowman, E.D.; Schetter, A.J.; Horikawa, I.; Mathe, E.A.; Jen, J.; Yang, P.; Sugimura, H.; Gemma, A.; Kudoh, S.; Croce, C.M.; Harris, C.C. MiR-21 is an EGFR-regulated anti-apoptotic factor in lung cancer in neversmokers. Proc. Natl. Acad. Sci. USA., 2009, 106(29), 12085-12090.
Received: June 25, 2013

Revised: September 10, 2013

Accepted: May 13, 2014 